\title{
Glycoprotein Iib/Iiia Inhibitors in Acute ST-Segment Elevation Myocardial Infarction: Evaluation of Clinical Practice and Cost/Efficacy Analysis
}

Cuny $\mathbf{P}^{1}$, Benmiloud $\mathbf{S}^{1}$, Oliary $\mathbf{J}^{1}$, Dillinger $\mathbf{J G}^{2}$, Sideris $\mathbf{G}^{2}$, Henry $\mathbf{P}^{2}$ and Manzo-Silberman $\mathbf{S}^{*}$

${ }^{1}$ Department of Pharmacy, Lariboisière Hospital (APHP), 2 Rue Ambroise Paré, France

${ }^{2}$ Department of Cardiology, Lariboisière Hospital (APHP), 2 Rue Ambroise Paré, Paris, France

\begin{abstract}
Associated to primary percutaneous coronary intervention (pPCl), pharmacotherapy in acute ST-Segment elevation myocardial infarction (STEMI) patients have transformed the management of the acute phase. Use of glycoprotein Ilb/llla inhibitors (GPI) remains debatable, level of guidelines has been modified in the successive editions of guidelines. In the latest European Society of Cardiology guidelines, GPI have a Ilb B level in upstream use and Ila $\mathrm{C}$ in bail out during $\mathrm{pPCl}$ procedure. In front of the varying recommendations, we analysed clinical characteristics of patients with ST-Segment elevation myocardial infarction according to the use of GPI. We evaluate complications during hospitalization, particularly bleeding events. The cost of patients' management was also analysed.

We conducted a retrospective, descriptive and monocentric study from January 2010 to December 2012 including all consecutive STEMI patients with symptoms evolving for less than 12 hours treated by pPCI.

GPI were administered as recommended in patients with high thrombotic risk, low bleeding risk, with early presentation and more likely anterior location. Despite an initial more severe clinical presentation, no statistical difference among each group on in-hospital complications and duration of hospital stay was observed. Nevertheless patients treated with abciximab have a significant higher cost of overall management compared to HNF only $(+30 \%)$ or other GPI (+37\%). In selected clinical indications, in line with the European guidelines, GPI use appears safe, efficient and cost effective with regards to eptifibatide/tirofiban.
\end{abstract}

Keywords: Antiplatelet therapy; Glycoprotein IIb-IIIa inhibitors; ST-Segment elevation myocardial infarction; Primary percutaneous coronary intervention; Cost effectiveness

Abbreviations: ACS: Acute Coronary Syndrome; GPI: Glycoprotein IIb-IIIa Inhibitors; ICCU: Intensive Cardiac Care Unit; LVEF: Left Ventricular Ejection Fraction; PPCI: Primary Percutaneous Coronary Intervention; STEMI: ST-Segment Elevation Myocardial Infarction.

\section{Introduction}

In-hospital mortality related to ST-Segment elevation myocardial infarction (STEMI) patients depends of many settings: age, Killip classification, comorbid condition (diabetes, kidney failure) but also management delay and treatment delivered. Recent studies $[1,2]$, have highlighted the relationship between decrease in acute and long term mortality and guidelines guided therapy regarding myocardial reperfusion. While HORIZON MI study [35], has compared bivaluridin versus heparin plus a glycoprotein IIb/ IIIa inhibitor (GPI) in patients with STEMI undergoing primary percutaneous coronary intervention (pPCI), and showed a decreased 1 -year cardiac mortality $(2.1 \%$ versus $3.8 \%, \mathrm{p}=0.005)$ and all-cause mortality $(3.5 \%$ versus $4.8 \%, \mathrm{p}=0.037)$ in the bivalirudin group. Some recent studies, NAPLES 3 study [6], and HEAT-PPCI study, have reported conflicting results with reduced incidence of major adverse ischemic events, with no increase in bleeding complications in the heparin group [7]. In the EUROMAX study, upstream use of bivalirudin, for pPCI, reduces major bleeding compared with both patients treated with heparin added to routine or even bailout GPI [8], reviving the debates. As well European and American guidelines have, regularly, modified the level and class of recommendation of GPI [9-14]. In 2012, the European guidelines [12] limit the routine use of GPI with a class IIb level B recommandation, proposed that GPI should be considered in bailout therapy in case of thrombotic complication (class IIa, level C) and expressed that in high risk patient GPI may be used in upstream (class IIb, level A for abciximab, B for Eptofibatide and Tirofiban).

Even with various clinical studies and pharmacological rational, in front of the varying recommendations and contradictory results of randomized trials, we decided to evaluate in a single tertiary center the real life indications of GPI. Among STEMI patients we analyzed clinical characteristics, complications during hospitalization, particularly bleeding events as well as cost issues related to the drug used.

\section{Methods}

\section{Method}

This study was retrospective, descriptive and monocentric from January 2010 to December 2012. Inclusion criteria were adult patients with STEMI admitted to the coronary care unit (CCU) at Lariboisière university hospital (Paris, France) and treated by pPCI. Patients were eligible if admitted for de novo STEMI within $12 \mathrm{~h}$ from symptoms

*Corresponding author: Dr. Stéphane Manzo-Silberman, Département of Cardiology, Lariboisière Hospital (APHP), Université Paris VII, INSERM UMRS 942, 2 Rue Ambroise Paré - 75475 Paris cedex 10, France, Tel: +331499582 09/ +3366113 53 34; E-mail: stephane.manzosilberman@aphp.fr ; stephanesilberman@hotmail.com

Received February 08, 2018; Accepted March 06, 2018; Published March 13, 2018

Citation: Cuny P, Benmiloud S, Oliary J, Dillinger JG, Sideris G, et al. (2018) Glycoprotein lib/liia Inhibitors in Acute ST-Segment Elevation Myocardial Infarction: Evaluation of Clinical Practice and Cost/Efficacy Analysis. Cardiovasc Pharm Open Access 6: 236. doi: 10.4172/2329-6607.1000236

Copyright: (c 2018 Cuny P, et al. This is an open-access article distributed unde the terms of the Creative Commons Attribution License, which permits unrestricted use, distribution, and reproduction in any medium, provided the original author and source are credited. 
onset to pPCI. Exclusion criteria were patients with medical history: prior myocardial infarction, prior PCI or prior coronary artery bypass graft, cardiogenic shock at admission, cardiac arrest. The aim of our study was to define the clinical characteristics of patients with STEMI according to the use of GPI, to compare in hospital major ischaemic and bleeding events as well as global in hospital cost.

According to the treatment administered, we analysed cardiovascular risk factors, the management delay between the onset of chest pain and arrival in coronary angiography, the culprit artery, MI location, vascular access, transfusion, heart failure during hospitalization, duration of hospital stay, LVEF by transthoracic Doppler ultrasound (ETT) at hospital discharge and hospital management cost.

\section{Data collection}

To compare patients with or without administration of GPI, we used angiography database and medical files. Data of consecutive patients admitted from 2010 to 2012 were retrospectively collected and recorded. We reported also bleeding events and costs. The duration of hospitalization in ICCU and in the general cardiology ward were also recorded.

\section{Cost analyses}

Costs evaluation of patient's management was performed using data analytical accounting of Assistance Publique des Hôpitaux de Paris (data from the Public Health Department). All expenses of the year are listed by hospital department and unit. Direct costs included: human resources (medical, nursing, other), drugs, labile blood products, implantable medical devices. Indirect costs were: loads induced laboratory, functional tests, imaging, for example. It was obtained an average cost per day and patient of a unit or service.

\section{Statistical analyses}

Three independent groups (abciximab, eptifibatide / tirofiban or without GPI) were compared. Discrete variables were presented as percentages and counts. For quantitative variables, mean $+/$ - standard deviation were calculated. Discrete variables were analyzed by a group Chi-square test $(\chi 2)$. Continuous variables groups were compared by analysis of variance. For all analyses, a $p$ value $<0.05$ was considered to be statistically significant.

\section{Results}

From January 2010 to December 2012, 534 STEMI patients were admitted in our department, among them 294 patients fulfilled the inclusion criteria and were analyzed. We distinguished three groups:

- The "abciximab" group (187 patients) included all patients treated with this drug during the acute phase of ACS.

- The tirofiban / eptifibatide" group comprised 39 patients who received one of the two molecules (tirofiban: 15 patients and eptifibatide: 24 patients).

- 68 patients did not receive any GPI during the acute phase of STEMI: no-GPI group. Note that these patients may have received bivalirudin (27 patients) during the pPCI.

\section{Clinical characteristics}

Clinical characteristics at admission are presented in Table 1. According to the use and the type of GPI, we reported only sex and age difference between groups. Male received more GPI than women $(\mathrm{p}=0.01)$. The average age of all patients was 60 years $(+/-14$ years $)$, patients without GPI were older, particularly men. Other cardiovascular risk factors did not differ between the three groups.

\section{Medical management delay}

The average time between chest pain and coronary angiography (Table 2) was 3.9 hours (+/-2.5 hours). It was significantly lower in the abciximab group 3.5 hours $(+/-2.3)(\mathrm{p}=0.01)$, and much longer among patient who received no GPI ( $4.1+/-2.6$ hours). Among women (not shown), there was no significant difference between groups. On the opposite among men under 60 years, the delay was increased in the eptifibatide/tirofiban group compared to the other two groups $(\mathrm{p}=0.03)$.

\section{Angioplasty}

The anatomical location of STEMI was obtained from electrocardiographic patterns. Acute myocardial infarction affected inferior wall in $45.9 \%$ of patients and anterior wall in $41.8 \%$. There was no significant difference among groups. Culprit coronary artery was reported for each patient (Table 2) and was predominantly the left anterior descending artery (46.3\%). Thus, among patients treated with tirofiban or eptifibatide, left anterior descending artery was less

\begin{tabular}{|c|c|c|c|c|c|}
\hline & $\begin{array}{c}\text { Total } \\
(n=294)\end{array}$ & $\begin{array}{c}\text { Abciximab } \\
(n=187)\end{array}$ & $\begin{array}{l}\text { Tirofiban Eptifibatide } \\
\qquad(n=39)\end{array}$ & $\begin{array}{l}\text { No-GPI } \\
(n=68)\end{array}$ & p value \\
\hline Age (y) mean (SD) & $60(14.0)$ & $58(12.4)$ & $61(15.7)$ & $65(15.7)$ & 0.02 \\
\hline Men $(y)$ mean (SD) & $57(12)$ & $57(10.8)$ & $60(15.8)$ & $59(13)$ & 0.01 \\
\hline Women $(y)$ mean (SD) & $70(16.3)$ & $66(16.6)$ & $67(14.6)$ & $75(15.3)$ & 0.86 \\
\hline$<60$ years $n(\%)$ & $157(53.4 \%)$ & $106(67.5 \%)$ & $23(14.6 \%)$ & $28(17.9 \%)$ & \multirow{3}{*}{0.01} \\
\hline $60-74$ years $n(\%)$ & $83(28.2 \%)$ & $57(68.7 \%)$ & $7(8.4 \%)$ & $19(22.9 \%)$ & \\
\hline$\geq 75$ years $n(\%)$ & $54(18.4 \%)$ & $24(44.4 \%)$ & $9(16.7 \%)$ & $21(38.9 \%)$ & \\
\hline Men n (\%) & $232(78.9 \%)$ & $157(83.9 \%)$ & $30(76.9 \%)$ & $45(66.2 \%)$ & 0.01 \\
\hline BMI (kg.m-2) mean (SD) & $26(3.6)$ & $26,3(3.6)$ & $25.3(4.0)$ & $25.5(3.5)$ & 0.63 \\
\hline Diabetes mellitus n (\%) & $44(15 \%)$ & $27(14.5 \%)$ & $6(15.4 \%)$ & $11(16.2 \%)$ & 0.94 \\
\hline High Blood Pressure n (\%) & $112(38.1 \%)$ & $73(39 \%)$ & $13(33.3 \%)$ & $26(38.2 \%)$ & 0.80 \\
\hline Dyslipidemia n (\%) & $122(41.5 \%)$ & $80(42.8 \%)$ & $16(41 \%)$ & $26(38.2 \%)$ & 0.81 \\
\hline Active smoking $\mathrm{n}(\%)$ & $150(51.0 \%)$ & $99(52.9 \%)$ & $23(58.8 \%)$ & $28(41.2 \%)$ & 0.19 \\
\hline Obesity n (\%) & $44(15.0 \%)$ & $31(16.6 \%)$ & $5(12.8 \%)$ & $8(11.8 \%)$ & 0.60 \\
\hline Cardiovascular heredity $\mathrm{n}(\%)$ & $80(27.2 \%)$ & $53(28.3 \%)$ & $11(28.2 \%)$ & $16(23.5 \%)$ & 0.74 \\
\hline
\end{tabular}

Table 1: Baseline clinical characteristics. 
Page 3 of 6

\begin{tabular}{|c|c|c|c|c|c|}
\hline & $\begin{array}{c}\text { Total } \\
(n=294)\end{array}$ & $\begin{array}{c}\text { Abciximab } \\
(n=187)\end{array}$ & $\begin{array}{l}\text { Tirofiban Eptifibatide } \\
\qquad(\mathrm{n}=39)\end{array}$ & $\begin{array}{l}\text { No-GPI } \\
(\mathrm{n}=68)\end{array}$ & $p$ value \\
\hline $\begin{array}{c}\text { Medical management delay } \\
\text { Hours mean (SD)Medical management }\end{array}$ & $3.9(2.5)$ & $3.5(2.3)$ & $4.9(3.1)$ & $4.1(2.6)$ & 0.01 \\
\hline $\begin{array}{c}\text { among men }<60 \text { years } \\
\text { hours mean (SD) }\end{array}$ & $3.6(2.5)$ & $3.4(2.3)$ & $4.7(3.4)$ & $3.7(2.4)$ & 0.03 \\
\hline \multicolumn{6}{|c|}{ Time of Administration GP Ilb-llla Inhibitors } \\
\hline Upstream n (\%) & $16(7.1 \%)$ & $14(7.5 \%)$ & $2(5.1 \%)$ & $\mathrm{x}$ & * \\
\hline During/After PCI n (\%) & $190(84.1 \%)$ & $155(82.9 \%)$ & $35(89.7 \%)$ & $\mathrm{x}$ & 0.28 \\
\hline Not specified n (\%) & $20(8.8 \%)$ & $18(9.6 \%)$ & $2(5.2 \%)$ & $x$ & $*$ \\
\hline \multicolumn{6}{|c|}{ MI Location } \\
\hline Anterior/apical n (\%) & $123(41.8 \%)$ & $87(46.5 \%)$ & $9(23.1 \%)$ & $27(39.7 \%)$ & 0.02 \\
\hline Circumferential n (\%) & $3(1.1 \%)$ & $3(1.6 \%)$ & $0(0 \%)$ & $0(0 \%)$ & $*$ \\
\hline Lateral n (\%) & $28(9.5 \%)$ & $9(4.8 \%)$ & $12(30.8 \%)$ & $7(10.3 \%)$ & 0.01 \\
\hline Inferior $\mathbf{n}(\%)$ & $135(45.9 \%)$ & $86(46 \%)$ & $17(43.6 \%)$ & $32(47.1 \%)$ & 0.94 \\
\hline Undeterminated $\mathbf{n}(\%)$ & $5(1.7 \%)$ & $2(1.1 \%)$ & $1(2.5 \%)$ & $2(2.9 \%)$ & * \\
\hline \multicolumn{6}{|c|}{ Culprit Coronary Artery } \\
\hline Left Anterior descending artery $n(\%)$ & $136(46.2 \%)$ & $95(50.8 \%)$ & $10(25.6 \%)$ & $31(45.6 \%)$ & 0.02 \\
\hline Left Circumflex n (\%) & $55(18.8 \%)$ & $26(13.9 \%)$ & $14(35.9 \%)$ & $15(22.1 \%)$ & 0.03 \\
\hline Right coronary artery $\mathrm{n}(\%)$ & $103(35 \%)$ & $66(35.3 \%)$ & $15(38.5 \%)$ & $22(32.3 \%)$ & 0.81 \\
\hline \multicolumn{6}{|c|}{ Adjonctive Antiplatelet Therapy } \\
\hline Clopidogrel n (\%) & $199(67.7 \%)$ & $136(72.7 \%)$ & $25(64.1 \%)$ & $38(55.9 \%)$ & 0.03 \\
\hline Prasugrel n (\%) & $66(22.5 \%)$ & $40(21.4 \%)$ & $8(20.5 \%)$ & $18(26.5 \%)$ & 0.66 \\
\hline Ticagrelor $\mathbf{n}(\%)$ & $16(5.4 \%)$ & $4(2.1 \%)$ & $3(7.7 \%)$ & $9(13.2 \%)$ & 0.01 \\
\hline Not specified $\mathbf{n}(\%)$ & $13(4.4 \%)$ & $7(3.8 \%)$ & $3(7.7 \%)$ & $3(4.4 \%)$ & * \\
\hline
\end{tabular}

Not evaluated

Table 2: Primary PCl characteristics.

often involved $(25.6 \%, \mathrm{p}=0.02)$ than in abciximab group. For them, the Circumflex was predominantly the culprit coronary artery. Radial access was mainly used in $91.2 \%$ of the procedures without any difference between groups on access site.

Time of GPI administration, upstream or during/after PCI, showed no difference between the groups $(\mathrm{p}=0.28)$. Thromboaspiration during angioplasty was performed in the majority of the patients in abciximab group (62\%), in $41 \%$ of the patients in the tirofiban/eptifibatide group and in $39.7 \%$ in the no-GPI group. There is a significant difference between the groups ( $\mathrm{p}=0.01$ ).

In combination with aspirin, the most frequent oral antiplatelet therapy loaded at the initial acute phase of ACS was clopidogrel (67.7\%), a fortiori for patients treated with GPI (80.9\%). In contrast, ticagrelor was administered more frequently in the no-GPI group. Prasugrel was administered in $22.5 \%$ of patients, without difference among groups. All the culprit lesions were successfully treated, with final TIMI grade flow $>2$.

\section{Left ventricular ejection fraction}

The left ventricular ejection fraction (LVEF) was analysed at hospital discharge in all patients. In $79.6 \%$ of cases, LVEF was greater than or equal to $45 \%$. There was no significant difference among groups.

\section{In-hospital complications and duration of hospital stay}

No difference was found in in-hospital events between the three groups (Table 3). During the study period, the STEMI in-hospital mortality was $2.7 \%$. The mortality rate did not differ between the groups despite a trend of higher rate in the no-GPI group: $2.7 \% v s$. $0 \%$ vs. $4.4 \%, \mathrm{p}=0.76$. Transfusions were required in $4.4 \%$ of patients, with a higher trend in the group treated with small molecules (tirofiban and eptifibatide): $3.7 \%$ vs. $7.7 \%$ vs. $4.4 \%, \mathrm{p}=0.55$. Global duration of hospital stay was 5.6 days, without difference among groups.

\section{Cost analysis}

Cost analysis was presented in Table 4 . The cost of hospital stay per patient treated for STEMI was 5426 euros. No significant difference was found among groups on this endpoint. The overall cost was calculated by adding the cost of hospital stay (average of 5426 euros) and cost of medications (GPI). Overall cost was 6074 euros, and per day 1140 euros. Patients treated with abciximab had a higher overall cost, compared to other two groups $(\mathrm{p}=0.01)+37 \%$ compared to the tirofiban / eptifibatide" group and $+30 \%$ compared to the no-GPI group.

\section{Discussion}

In our French retrospective analysis, we found a large prescription of GPI: nearly $77 \%$ of patients treated within the first 12 hours of $d e$ novo STEMI. This percentage is higher than that of the FAST-MI registry $42.7 \%$ in 2010 [15]. This could be explained by the geographical characteristics with short transportation delays due to high PPCI centers density and the absence of fibrinolysis required in this network and a short median symptom to balloon delay. Pre-hospital and cath lab physicians' choice of therapeutic strategies were in line with the then prevailing European guidelines [10].

\section{Patients' characteristics}

The average age was 60 years $(+/-14)$; in women 69 years $(+/-$ $16.3)$ and men 57 years (+/-12). $21.1 \%$ of patients were women. The population of the study is comparable to population described in the FAST-MI 2010 registry and European registries [16-19]. 


\begin{tabular}{|c|c|c|c|c|c|}
\hline & $\begin{array}{c}\text { Total } \\
(n=294)\end{array}$ & $\begin{array}{c}\text { Abciximab } \\
(n=187)\end{array}$ & $\begin{array}{l}\text { Tirofiban Eptifibatide } \\
\qquad(n=39)\end{array}$ & $\begin{array}{l}\text { No-GPI } \\
(n=68)\end{array}$ & $p$ value \\
\hline Death n (\%) & $8(2.7 \%)$ & $5(2.7 \%)$ & $0(0 \%)$ & $3(4.4 \%)$ & 0.76 \\
\hline Acute renal failure $\mathrm{n}(\%)$ & $11(3.7 \%)$ & $6(3.2 \%)$ & $0(0 \%)$ & $5(7.3 \%)$ & 0.27 \\
\hline Left heart failure $\mathrm{n}(\%)$ & $6(2.0 \%)$ & $3(1.6 \%)$ & $0(0 \%)$ & $3(4.4 \%)$ & 0.45 \\
\hline Ventricular fibrillation $\mathrm{n}(\%)$ & $13(4.4 \%)$ & $10(5.3 \%)$ & $1(2.6 \%)$ & $2(2.9 \%)$ & 0.63 \\
\hline Recurrent MI n (\%) & $2(<0.1 \%)$ & $2(<0.1 \%)$ & $0(0 \%)$ & $0(0 \%)$ & \\
\hline Transfusion $\mathbf{n}(\%)$ & $13(4.4 \%)$ & $7(3.7 \%)$ & $3(7.7 \%)$ & $3(4.4 \%)$ & 0.55 \\
\hline $\begin{array}{l}\text { Duration of hospital stay (days) } \\
\text { mean (SD) }\end{array}$ & $5.61(4.87)$ & $5.73(5.18)$ & $4.87(3.24)$ & $5.70(4.80)$ & 0.56 \\
\hline $\begin{array}{l}\text { Duration of stay in ICCU (days) } \\
\text { mean (SD) }\end{array}$ & $4.08(1.95)$ & $4.16(1.99)$ & $4.10(2.19)$ & $3.85(1.66)$ & 0.53 \\
\hline
\end{tabular}

ICCU: Intensive Cardiac Care Unit; AMI: Acute myocardial infarction.

Table 3: In-hospital events and duration of hospital stay.

\begin{tabular}{|c|c|c|c|c|c|}
\hline & $\begin{array}{c}\text { Total } \\
(n=294)\end{array}$ & $\begin{array}{l}\text { Abciximab } \\
(n=187)\end{array}$ & $\begin{array}{l}\text { Tirofiban Eptifibatide } \\
\qquad(n=39)\end{array}$ & $\begin{array}{l}\text { no-GPI } \\
(n=68)\end{array}$ & p value \\
\hline \multicolumn{6}{|c|}{ Cost of Hospital Stay (Euros) } \\
\hline Cost of hospital stay mean (SD) & $5426(5167)$ & $5761(6058)$ & $4644(2884)$ & 4947 (2995) & 0.10 \\
\hline Cost of hospital stay per day mean (SD) & $982(113)$ & $987(117)$ & $979(67)$ & $968(122)$ & 0.28 \\
\hline \multicolumn{6}{|c|}{ Overall Cost : Medications and Hospital Stay (Euros) } \\
\hline Overall cost mean (SD) & $6074(5204)$ & $6676(6058)$ & $4864(2881)$ & $5111(2960)$ & 0.09 \\
\hline $\begin{array}{c}\text { Overall cost } \\
\text { per day mean (SD) }\end{array}$ & $1140(176)$ & $1209(162)$ & $1036(82)$ & $1010(148)$ & 0.01 \\
\hline
\end{tabular}

Table 4: Cost analysis.

However, in terms of cardiovascular risk factors our population differed from the population reported in the 2010 nationwide snapshot registry [15]. The percentage of diabetic, dyslipidemic and/or obese patients were comparable, but smokers were more represented in our population (50\% versus $40 \%)$ and high blood pressure less retrieved ( $38 \%$ versus $47 \%)$.

Patients who were not treated with GPI were significantly older. The choice to not administrate GPI have probably been guided first by bleeding avoidance strategies [20,21]. On the opposite, among younger patients, at lower bleeding risk, the choice was oriented toward a more aggressive anti-ischaemic strategy and abciximab was dispensed more willingly.

The prescription of a GPI seems not influenced by the other risk factor, especially diabetes mellitus: the percentage of diabetics was similar in both groups studied. Despite diabetic patients are at higher risk of thrombosis, with a higher platelet reactivity [22], and for which the GPI have been shown a net clinical benefit [23].

The average time between chest pain and coronary angiography was 3.9 hours ( $+/-2.5$ hours). This time was higher in the eptifibatide / tirofiban group compared to the other two groups, particularly among men under 60 . These patients, when seen later were less likely treated with abciximab. However, identification of significant thrombotic burden during coronary angiography and their low bleeding risk may have oriented the drug prescription.

We reported that the abciximab group included patients treated earlier with anterior and apical MI locations. In fact, these patients would more benefit of a more aggressive antiplatelet strategy [24,25]. These characteristics are those indicated in the European guidelines [12]. Interestingly electrical diagnosis of MI related to circumflex occlusion may be initially difficult, leading to a delayed medical management. In the present study, patients with occluded circumflex artery had in fact later medical care, and are more represented in tirofiban/eptifibatide treated group.
The radial access is used in $91.2 \%$ of patients as recommended guidelines [12]. Although the risk of bleeding is increased with the femoral access $[26,27]$, approach was not a discriminant parameter for the use of GPI.

\section{In-hospital events}

The rate of post-MI complications are comparable to data from the French FAST-MI registry $[28,29]$, re-MI in $0.9 \%$ of patients $(<0.1 \%$ in our study), deaths in $5 \%$ of patients (2.7\% in our study) and transfusion in $3.2 \%$ of patients ( $4.4 \%$ in our study). LVEF retrieved in our study was similar to the one reported in the French data $49.7 \%$ and $50.4 \%$ respectively. Our analysis didn't retrieve any difference among groups regarding in-hospital events. The risk of acute renal failure, left heart failure and recurrence of MI do not differ between the groups with and without GPI, but the number of patients was low.

In our study the use of GPI did not increase the rate of bleeding. The duration of hospital stay was 5.6 days This duration was relatively shorter than those reported in FAST MI [28], 8 days (+/-7.8 days), with 4.4 days $(+/-4.2$ days) in ICCU. These shorter stays may be related to the fact that we excluded NSTEMI and patients with more severe presentation at admission like cardiogenic shock and cardiac arrested patient. GPI did not change the stay's duration of patients.

\section{Cost}

Per patient, the cost of hospital stay was 5426 euros (1008-59583). While no difference regarding hospital stay's cost was found between groups, the overall cost per patient and per day differed between groups. Anticoagulants and antiplatelet drugs have a low price and do not influence. Patients treated with abciximab had the highest overall cost. In our hospital, abciximab's treatment, intra venous bolus and infusion is 915 euros, 197 euros with tirofiban, 235 euros with eptifibatide and 407 euros with bivalirudin. Prices explain the difference in the overall cost, as the hospitalization's duration was similar. An American study $[30,31]$, compared the overall cost for patients with STEMI treated by 
angioplasty (associated with GPIIb-IIIa inhibitors or fibrinolysis) to those treated with angioplasty alone. There is no significant difference between groups on this endpoint.

\section{Limits}

This study showed limits. First of all, we conducted a retrospective and monocentric analysis with its inherent bias related to patient's recruitment specificity, local practice. Secondly, these results should also be interpreted cautiously in view of the small size of the population. Due to the limited period and the single centre analysis, it was not possible to analyse a temporal trend. Lastly, our records did not included long term parameters. To compare GPI we had only surrogate short term parameters.

\section{Conclusion}

Our retrospective monocentric analysis reported that patients to whom GPI were administered were more likely young, with early presentation of an anterior MI related to left anterior descending artery lesion.

No difference between GPI or the no-GPI groups were found regarding in-hospital complications and duration of hospital stay. Solely patients treated with abciximab had a higher cost of overall management.

As registries are needed to verify that real-life daily practice is in keeping with what is recommended in the guidelines, in fact our retrospective study met 2012 ESC'guidelines [12]. This rational choice of treatment according to patient profile during management of acute MI resulted in event rates, especially haemorrhagic, not different. In these selected indications, small molecules show a better cost-efficacy profiles.

\section{Abbreviated Title}

GPIIb/IIIa inhibitors in STEMI: patients' characteristics and cost/ efficacy analysis.

\section{References}

1. Jernberg T, Johanson P, Held C, Svennblad B, Lindback J, et al. (2011) Association between adoption of evidence-based treatment and survival for patients with ST-elevation myocardial infarction. JAMA 305: 1677-1684.

2. Steg P, Eagle K, Goodman S, Anderson F, Granger C, et al. (2007) Decline in Rates of Death and Heart Failure in Acute Coronary Syndromes, 1999-2006. J Am Med Assoc 297: 1892-1900.

3. Stone G, Witzenbichler B, Guagliumi G, Peruga J, Brodie B, et al. (2008) Bivalirudin during primary $\mathrm{PCl}$ in acute myocardial infarction. $\mathrm{N}$ Engl $\mathrm{J}$ Med 358: $2218-2230$.

4. Mehran R, Lansky AJ, Witzenbichler B, Guagliumi G, Peruga JZ, et al. (2009) Bivalirudin in patients undergoing primary angioplasty for acute myocardial infarction (HORIZONS-AMI): 1-year results of a randomised controlled trial. Lancet 374: 1149-1159.

5. Stone GW, Witzenbichler B, Guagliumi G, Peruga JZ, Brodie BR, et al. (2011) Heparin plus a glycoprotein Ilb/llla inhibitor versus bivalirudin monotherapy and paclitaxel-eluting stents versus bare-metal stents in acute myocardial infarction (HORIZONS-AMI): final 3-year results from a multicentre, randomised controlled trial. Lancet 377: 2193-2204.

6. Briguori C, Visconti G, Focaccio A, Donahue M, Golia B, et al. (2015) Nove approaches for preventing or limiting events (Naples) III trial: Randomized comparison of bivalirudin versus unfractionated heparin in patients at increased risk of bleeding undergoing transfemoral elective coronary stenting. JACC Cardiovasc Interv 8: 414-423.

7. Shahzad A, Kemp I, Mars C, Wilson K, Roome C, et al. (2014) Unfractionated heparin versus bivalirudin in primary percutaneous coronary intervention (HEAT-PPCI): An open-label, single centre, randomised controlled trial. Lance 384: $1849-1858$.

8. Zeymer U, van 't Hof A, Adgey J, Nibbe L, Clemmensen P, et al. (2014) Bivalirudin is superior to heparins alone with bailout GP Ilb/llla inhibitors in patients with ST-segment elevation myocardial infarction transported emergently for primary percutaneous coronary intervention: a pre-specified analysis from the Euromax tria. Eur Heart J 35: 2460-2467.

9. O'Gara PT, Kushner FG, Ascheim DD, Casey DE, Chung MK, et al. (2013) ACCF/AHA guideline for the management of ST-elevation myocardial infarction: a report of the American College of Cardiology Foundation/American Heart Association Task Force on Practice Guidelines. J Am Coll Cardiol 61 e78-140.

10. Van de Werf F, Bax J, Betriu A, Blomstrom-Lundqvist C, Crea F, et al Management of acute myocardial infarction in patients presenting with persistent ST-segment elevation: the Task Force on the Management of STSegment Elevation Acute Myocardial Infarction of the European Society of Cardiology. Eur Heart J 2008 29: 2909-2945.

11. Wijns W, Kolh P, Danchin N, Di Mario C, Falk V, et al. (2010) Guidelines on myocardial revascularization. Eur Heart J 31: 2501-2555.

12. Steg $P$, James S, Atar D, Badano L, Blomstrom-Lundqvist C, et al. (2012) ESC Guidelines for the management of acute myocardial infarction in patients presenting with ST-segment elevation. The Task Force on the management of ST-segment elevation acute myocardial infarction of the European Society of Cardiology (ESC). Eur Heart J 33: 2569-2619.

13. Windecker S, Kolh P, Alfonso F, Collet JP, Cremer J, et al. (2014) ESC/EACTS Guidelines on myocardial revascularization: The Task Force on Myocardia Revascularization of the European Society of Cardiology (ESC) and the European Association for Cardio-Thoracic Surgery (EACTS)Developed with the special contribution o. Eur Heart J 35: 2541-2619.

14. Roffi M, Patrono C, Collet J-P, Mueller C, Valgimigli M, et al. (2015) ESC Guidelines for the management of acute coronary syndromes in patients presenting without persistent ST-segment elevation. Eur Heart J 2015: ehv320.

15. Puymirat E, Simon T, Steg PG, Schiele F, Guéret P, et al. (2012) Association of changes in clinical characteristics and management with improvement in survival among patients with ST-elevation myocardial infarction. JAMA 308: 998-1006.

16. Hvelplund A, Galatius S, Madsen M, Rasmussen JN, Rasmussen S, et al (2010) Women with acute coronary syndrome are less invasively examined and subsequently less treated than men. Eur Heart J 31:684-690.

17. Schiele F, Meneveau N, Seronde MF, Descotes-Genon V, Chopard R, et al. (2011) Propensity score-matched analysis of effects of clinical characteristics and treatment on gender difference in outcomes after acute myocardial infarction. Am J Cardiol 108: 789-798.

18. Jakobsen L, Niemann T, Thorsgaard N, Nielsen TT, Thuesen L, et al. (2012) Sex- and age-related differences in clinical outcome after primary percutaneous coronary intervention. Eurolntervention 8: 904-911.

19. Velders $M$, Boden $H$, van Boven AJ, van der Hoeven BL, Heestermans ACM et al. (2013) Influence of gender on ischemic times and outcomes after STelevation myocardial infarction. Am J Cardiol 111: 312-318.

20. Marso SP, Amin AP, House JA, Kennedy KF, Spertus JA, et al. (2010) Messenger JC RJNCDR. Association between use of bleeding avoidance strategies and risk of periprocedural bleeding among patients undergoing percutaneous coronary intervention. JAMA 303: 2156-64.

21. Stacie Daugherty, Lauren Thompson, Sunghee Kim, Sunil Rao, Sumee Subherwal, et al. (2014) Patterns of Use and Comparative Effectiveness of Bleeding Avoidance Strategies in Men and Women Following Percutaneous Coronary Interventions: An Observational Study from the National Cardiovascular Data Registry. J Am Coll Cardiol 61: 2070-78.

22. Wiviott SD, Braunwald E, Angiolillo DJ, Meisel S, Dalby AJ, et al. (2008) Greate clinical benefit of more intensive oral antiplatelet therapy with prasugrel in patients with diabetes mellitus in the trial to assess improvement in therapeutic outcomes by optimizing platelet inhibition with prasugrel-Thrombolysis. Circulation 118: 1626-36.

23. Rakowski T, Siudak Z, Dziewierz A, Birkemeyer R, Legutko J, et al. (2009) Early abciximab administration before transfer for primary percutaneous coronary interventions for ST-elevation myocardial infarction reduces 1-year mortality in patients with high-risk profile. Am Heart J 158:5 69-75. 
Citation: Cuny P, Benmiloud S, Oliary J, Dillinger JG, Sideris G, et al. (2018) Glycoprotein lib/liia Inhibitors in Acute ST-Segment Elevation Myocardial Infarction: Evaluation of Clinical Practice and Cost/Efficacy Analysis. Cardiovasc Pharm Open Access 6: 236. doi: 10.4172/2329-6607.1000236

24. Huber K, Holmes DR, van 't Hof AW, Montalescot G, Aylward PE, et al. (2010) Use of glycoprotein Ilb/llla inhibitors in primary percutaneous coronary intervention: insights from the APEX-AMI trial. Eur Heart J 31: 1708-1716.

25. Van't Hof AWJ, Ten Berg J, Heestermans T, Dill T, Funck RC, et al. (2008) Prehospital initiation of tirofiban in patients with ST-elevation myocardia infarction undergoing primary angioplasty (On-TIME 2): a multicentre, doubleblind, randomised controlled trial. Lancet 372: 537-46.

26. Hamon M, Pristipino C, Di Mario C, Nolan J, Ludwig J, et al. (2013) Consensus document on the radial approach in percutaneous cardiovascular interventions: position paper by the European Association of Percutaneous Cardiovascular Interventions and Working Groups on Acute Cardiac Care and Thrombosis of the European Society. Euro Intervention 8: 1242-51.

27. Feldman D, Swaminathan R, Kaltenbach L, Baklanov D, Kim L, et al. (2013) Adoption of radial access and comparison of outcomes to femoral access in percutaneous coronary intervention: an updated report from the national cardiovascular data registry (2007-2012). Circulation 127: 2295-306
28. Hanssen M, Cottin Y, Khalife K, Hammer L, Goldstein P, et al. (2010) French Registry on Acute ST-elevation and non ST-elevation Myocardial Infarction 2010. FAST-MI. Heart 98: 699-705.

29. Danchin N, Coste P, Ferrières J, Steg PG, Cottin Y, et al. (2008) Comparison of thrombolysis followed by broad use of percutaneous coronary intervention with primary percutaneous coronary intervention for ST-segment-elevation acute myocardial infarction. Circulation 118: 268-276.

30. Coleman $\mathrm{Cl}$, McKay RG, Boden WE, Mather JF, White CM, et al. (2006) Effectiveness and cost-effectiveness of facilitated percutaneous coronary intervention compared with primary percutaneous coronary intervention in patients with ST-segment elevation myocardial infarction transferred from community hospitals. Clin Ther 28: 1054-1062.

31. Ottani F, La Vecchia L, De Vita M, Catapano O, Tarantino F, et al. (2010) Comparison by meta-analysis of eptifibatide and tirofiban to abciximab in patients with ST-elevation myocardial infarction treated with primary percutaneous coronary intervention. Am J Cardiol 106: 167-174. 